\title{
Shift and dayworkers' absence: relationship with some terms and conditions of service
}

\author{
P. J. TAYLOR ${ }^{1}$, S. J. POCOCK, and R. SERGEAN \\ TUC Centenary Institute of Occupational Health, London School of Hygiene and \\ Tropical Medicine, London, WC1
}

\begin{abstract}
Taylor, P. J., Pocock, S. J., and Sergean, R. (1972). Brit. J. industr. Med., 29, 338-340. Shift and dayworkers' absence: relationship with some terms and conditions of service. A previous investigation in 29 organizations showed that although shift workers had less absence overall than their counterparts on days, some inconsistencies existed. These are now examined in relation to company sick pay schemes, details of shift rotas, weekly hours of work, and earnings. No evidence was found to associate sick pay or details of the rota with the ratio of shift-to-day absence. An association was found between gross pay and frequency of certified sickness absence such that the more highly paid the shift worker relative to the day worker, the less satisfactory his absence record. Sickness absence was also related, though less closely, to hours of work: the shorter the shift workers' hours relative to those of day workers, the better their attendance. The implications of these results are discusssed.
\end{abstract}

In a previous paper (Taylor, Pocock, and Sergean, 1972) the absence records of 965 pairs of male shift and day workers from 29 organizations were analysed over a two-year period. Each pair was matched for age and occupation. Although the results showed that overall the shift workers had less absence of all kinds than their counterparts on day work, the results from different firms were not wholly consistent.

The present paper briefly examines some factors in the working situation with which such inconsistency might be associated. These are: (1) the type of company sick pay scheme; (2) the detailed arrangements of working hours; (3) the length of the working week; and (4) average weekly earnings.

\section{Methods}

The means by which the pairs of men were identified and their absence records obtained was described in the earlier paper. Each participating organization was asked to complete a questionnaire about the hours of work, wages, and sick pay for each occupational group for

1Present address: Post Office Central HQ, 23 Howland Street, London W1P 6HQ. which they had collected absence data. Further discussions were held with each organization by one of us to ensure as far as possible that the information on hours and earnings was calculated in a similar manner.

The only practicable method of studying the absence of groups of shift workers was to compare them with matched groups of day workers in the same organizations. Thus all the results are based on the shift to day ratios of absence. Direct comparisons of shift workers in different companies would not be valid, due to differences in occupation, age, region, etc.

\section{Results}

As in the previous paper, we have restricted our analysis to those organizations and occupational groups for which absence data were available for 10 or more matched pairs of men. These results are based on the 24 sets of comparisons for which the firms were able to provide adequately detailed information on terms and conditions of service.

\section{Sick pay schemes}

In addition to the social security benefits available to all workers in this country, each organization in 
our sample operated its own company sick pay scheme. Of the two main types of scheme, the one in which the social security entitlement of an individual worker is 'made up' to a set proportion of the normal weekly wage (usually to full wage) was twice as common as the scheme involving a flat rate payment only. In only two cases of make-up schemes was the shift allowance not included in the amount to which pay was made up.

It is sometimes argued that shift workers who suffer no financial loss when absent from work through sickness (by participating in make-up schemes inclusive of the shift element) are more likely to lose time, relative to day workers, than are shift workers who receive sick pay at a flat rate or by having their wages made up without inclusion of the shift allowance. However, a comparison of the two groups was carried out using Wilcoxon's Rank Sum Test on the shift to day ratios of spells of certified sickness absence ( $n . d=0.52 ; P=0.60$ ). Thus there was no evidence of any relationship between the absence ratio and the kind of sick pay scheme in operation.

\section{Arrangement of working hours}

The six main types of shift work covered in this study were described in the previous paper. From those results we were unable to draw any firm conclusions about their relative merits with regard to absence.

There remains the possibility of effects from design differences within each type of main comparison group. It has been emphasized elsewhere (Sergean, 1971) that what constitutes 'permanent night work' or 'three-shift work' in one establishment may differ quite markedly from what is covered by these terms in another. Shift starting times, frequency and direction of change, continuity or discontinuity of the system, for example, may all vary and may result in behavioural differences. Even 'day work' is not a constant 0800 to 1600 hours, five-days-a-week activity.

Design differences of this kind existed within all six main comparison groups, but no correspondence was found between the degree of internal consistency and the degree of consistency in absence behaviour. This is not surprising when the variety of factors involved is considered. Moreover, it should be remembered that 'minor' features of a shift rota may affect the distribution of absence without necessarily affecting the overall amount. Manipulation of shift starting and finishing times under a three-shift system, for example, may result in a redistribution of short-term absence over the 24 hours while leaving the total lost time unaffected.

\section{Length of working hours and earnings}

Shift workers are commonly regarded as having a shorter working week than their counterparts on ciays and as enjoying higher earnings through the receipt of shift allowances. In fact, these inducements are often extended to day workers to encourage them to transfer to shift work.

With a few exceptions, average weekly hours and earnings from 24 cases in our sample generally confirmed this view. Not only was the basic working week for day workers slightly longer, but they also tended to work greater amounts of overtime. Although overtime working by day workers tends to narrow the financial gap created by shift allowances, it seldom closes it entirely, overtime working by shift workers themselves helping to maintain the differential (Table 1).

We examined the association between shift-to-day absence ratios and the shift-to-day ratios for hours and for pay. Table 2 shows the resulting rank correlations which were significant for certified sickness absence only. The relationship between group pay and spells of certified sickness is also shown in the Figure.

This suggests that certified sickness is related to hours and pay in the following manner:

that the shorter the hours of shift workers relative to day workers the less sickness absence they have compared to day workers;

TABLE 1

Average Weekly Hours and Earnings for Shift AND DAY Workers IN THE SAMPLE

\begin{tabular}{|c|c|c|}
\hline & $\begin{array}{c}\text { Total weekly } \\
\text { working hours }\end{array}$ & $\begin{array}{c}\text { Weekly } \\
\text { gross pay }\end{array}$ \\
\hline $\begin{array}{l}\text { Day } \\
\text { Shift } \\
\text { Shift-to-day } \\
\text { ratio }\end{array}$ & $\begin{array}{r}44 \cdot 3 \\
41 \cdot 7 \\
0.94\end{array}$ & $\begin{array}{l}£ 28.63 \\
£ 32.90 \\
£ \quad 1.15\end{array}$ \\
\hline
\end{tabular}

TABLE 2

Rank Correlation ( $\tau$ ) Between ShifT-to-day Ratios for (a) Absence and (b) Hours and Pay

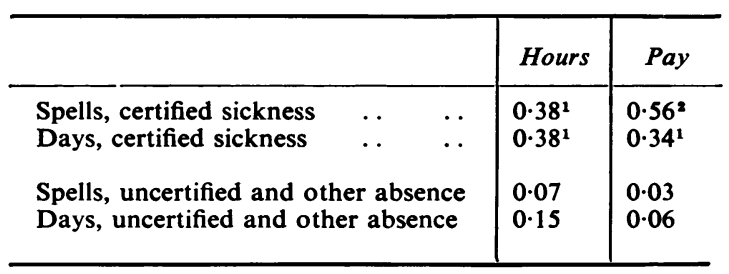

${ }^{1} \mathrm{P}<0.05 \quad{ }^{2} \mathrm{P}<0.01$ 


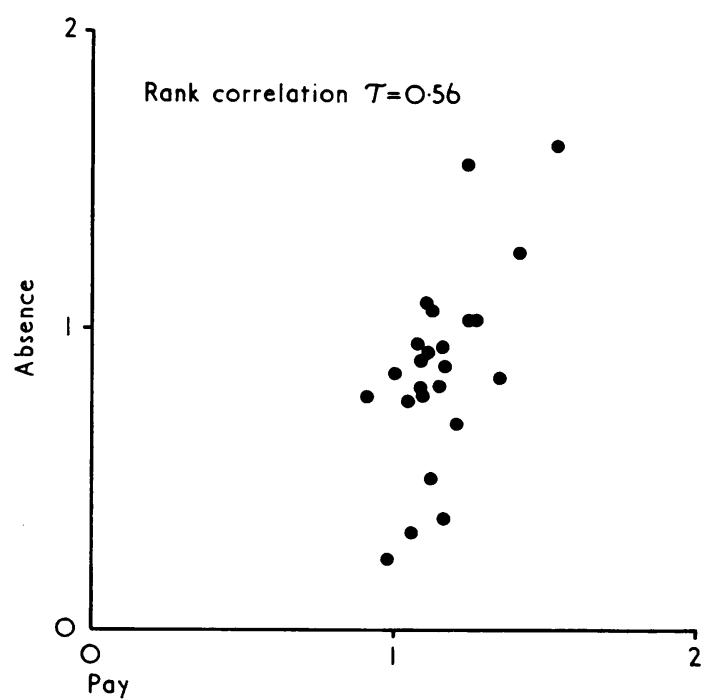

FIGURE Relationship between shift-to-day ratios for gross pay ( $x$ ) and spells of certified sickness absence $(y)$.

that the more favourable their gross earnings relative to day workers the more sickness absence they have compared to day workers.

If the association between hours and certified sickness absence (spells) is computed, removing the effect of pay, the value of the partial rank correlation $\tau$ falls to $\mathbf{0} \cdot 26$. A similar calculation for the association between pay and certified sickness absence (spells), removing the effect of hours, reduces $\tau$ only to $0 \cdot 50$. One may therefore conclude that the relative position of the shift workers to the day workers from the point of view of pay is a more potent factor in determining their relative amounts of sickness absence than is their relative position as regards hours of work - at least for the range of working hours involved here.

\section{Discussion}

Shift work, as shown in the previous paper, is associated in general with lower absence rates than day work. A variety of reasons have been advanced for this, e.g., that shift workers constitute a selfselected group, that they enjoy greater job satisfaction and are more highly motivated, that they include a higher proportion of married men with family responsibilities, and so on.

The present paper examines some other aspects of the working situation. It provides no evidence to support either the nature of sick pay provisions or the detailed design of the rota itself as determining influences. It does suggest, however, a moderate association between sickness absence and hours of work and a stronger one between sickness absence and pay. The trend is such that the more favourably placed financially is the shift man relative to his colleagues in a similar occupation on day work the less satisfactory is his record likely to be for certified sickness absence.

Evidence already exists to show that absence tends to increase with hourly wage rates (Shepherd and Walker, 1958), although this association is confounded by differences in type of work at different wage levels. The present results introduce another factor-gross earnings relative to those of men on the same job but on different hours of work.

This suggests that absentees may use as a standard of comparison their position not only generally vis-à-vis other wage earners outside the plant but relative to their counterparts on other hours of work within the firm. Such an internal standard would be reinforced in a fairly close-knit community where shift and day worker live in close proximity.

This finding appears to apply over a wide range of gross wage levels. Average earnings for the groups of day men in our comparisons ranged from $£ 18.78$ to $£ 43 \cdot 24$ : for shift men from $£ 20 \cdot 31$ to $£ 47.46$. The same shift-to-day ratio may hold at any point in the scale.

The existence of such a relationship between shiftto-day pay and absence rates suggests as a practical measure that shift differentials of exaggerated proportions should be avoided since they could lead to a higher level of absence on the part of shift workers. Shift workers whose prime motivation is financial may be less satisfactory attenders than those who are attracted to shift work by other non-financial incentives.

Although these conclusions can only be speculative they emphasize the need for taking account of gross earnings and hours of work in investigation of absence behaviour.

\section{References}

Sergean, R. (1971). Managing Shiftwork. Gower Press, London.

Shepherd, R. D., and Walker, J. (1958). Absence from work in relation to wage level and family responsibility. Brit. $J$. industr. Med., 15, 52-61.

Taylor, P. J., Pocock, S. J., and Sergean, R. (1972). Absenteeism of shift and day workers. Brit.J. industr. Med., 29, 208.

Received for publication October 4, 1971. 